\title{
Suicide Trends: Incidences from Pakistan
}

\author{
Rashida Valika and Dr. Amanat Ali Jalbani \\ SZABIST \\ Karachi, Pakistan
}

\begin{abstract}
:
The focus of this study is to provide understanding for human nature, the societal impact of suicides, to explore the trend and causes of suicide, and to create awareness about this sensitive and unlawful act. The main theme is a try to stop this inhuman act by helping the needed people by approaching the related authorities. This report is an effort to stop this sinful act by explaining the bad effects because this act can never eliminate the problems but on the other hand give rise to them. This whole effort can only bring about change, if everyone really wants to help others and contribute to get rid of this evil and unlawful act. This study discovers that suicide is an indication of the problems in the lives of many people such as financial, social or medical. The most common underlying disorder is depression, $30 \%$ to $70 \%$ of suicide victims suffer from major depression, no matter which strata of society they belong to. Most people who attempt suicide are confused about whether or not they want to die. They usually are desperate to find a way to remove or stop emotional pain. A suicide attempt is often a cry for help that ends in tragedy.
\end{abstract}

\section{INTRODUCTION}

The overall sense of helplessness and frustration is not only evident in our society but we have come to a point where the implications of it are taking a toll on us. The bomb is fast ticking and we are silent spectators just waiting and watching. We know the problems yet we remain aloof to them simply distancing ourselves from them as if it's about other people and not us. Even after 56 years of independence we as a nation are bogged down by major issues such as lack of justice, providence of basic amenities such as water, electricity, lack of infrastructure, demons such as unemployment and poverty, lawlessness to name a few. Physical frustration leads to emotional and mental frustrations and then finally people commit suicide to get rid of these problems. These issues are yet to be looked into, understood and answered.

The study is about:

- Mapping the trends of suicides in Pakistan in general and Karachi in particular.

- Discovering the major causes for suicide.

- Identifying the age factor and gender, marital status and social class involved in this act.

Study is conducted through quantitative measures.

\section{TRENDS OF SUICIDES IN GENERAL}

Suicide is an intentional and self-inflicted death. A uniquely in-human act, suicide occurs in all cultures. People who attempt or complete suicide usually suffer from extreme emotional pain and distress and feel unable to cope with their problems. They are likely to suffer from mental illness, particularly severe depression, and to feel hopeless about the future. Suicide ranks as a leading cause of death worldwide, making it a significant public health problem. The lines before refer to an act formally classified as suicides, but the more one thinks about it, the less clear the boundaries become [1].

Throughout the world, about 2000 people kill themselves each day. That's about 80 per hour, three quarters of a million a year. In the U.S., there are more than 80 deaths from suicide every day, 30,000 every year. This is the equivalent of a fully loaded jumbo jet crash every fifth day. From another perspective, you are more likely to kill yourself than be killed by someone else [2].

There are more suicides than the official numbers show, but there is no general agreement as to how many more. Estimates of under-reporting range from around $1 \%$ to $300 \%$. Reasons for under-reporting include:

- Families or family physicians may hide evidence due to the stigma of suicide.

- The determination of cause of-death is judged by local standards, which vary widely.

- The frequency of physician-assisted suicide for terminally ill is unknown, but, based on anecdotal evidence, is probably both substantial and increasing.

On the other side of the ledger, some doubtful cases are classified as suicides. These usually occur in institutions, such as prisons, hospitals, religious orders, and the military, which control their populations more-or-less completely.

The number of suicide attempts is also subject to dispute. Based on a range of studies, there are probably between 10-20 attempts for every suicide, or roughly 300,000600,000 attempts per year in the U.S. Yet more than half of suiciders kill themselves on their first try.

\section{SUICIDE TENDENCY IN PAKISTAN}

Suicide and attempted suicide are understudied subjects in Pakistan, an Islamic country where they are considered criminal offenses. In Pakistan, more than 40 million people are living in a condition of abject poverty; 70 million have no access to clean drinking water and 75 
million are deprived of health facilities [3]. At the time of Independence, the world was looking towards Pakistan, but today ours is 134th position among 174 nations with respect to poverty and human resource development. That means Pakistan is one of the 40 least developed and poorest countries. Pakistan in the year 2000 has seen an alarming rise in suicide cases, linked often to the national economy's sluggish growth and the military regime's preoccupation with things other than the welfare of its people. Since January 2000, over 233 suicides have been recorded in Karachi, the country's largest industrial center. Experts say exposure to cable TV, may be one of the factors responsible for causing depression. Increasing poverty could be another. While the impact of television maybe difficult to substantiate, the link between rising poverty and suicides is quite clear. In 1987-88 the total number of suicides stood at 98 . In 2000 it rose to over 400. The number of people living below the poverty line has almost doubled during this period. In Pakistan, suicide rates have alarmingly increased over the past three years, and a great majority of them are among the youth of this nation. In 1999 more than 332 people committed suicide. In the year 2000, 550 people were reported to have committed this heinous act. This figure jumped four-fold over the past one year when 2,386 suicidal deaths were reported. This means that there are approximately 6-7 suicides occurring everyday in Pakistan. Poverty rate in Pakistan is desperately high as more than 62.50 million (43.1\%) people are currently living below the poverty line. Poverty has hit the youth of the country severely with little, or no, access to educational health and employment opportunities. Since the inception of Pakistan, there has been no standalone youth policy to cater to the needs of a large base of the youth population (43 per cent of the total population). According to reported findings more than 350,000 people lost their jobs over the past three years, in the name of downsizing, rightsizing and smart sizing. The largest groups among the affected were the youths of Pakistan. The cumulative effect of all this has been the lack of development and poor socio-economic status among the young and middle-aged. Such reasons are behind the alarming rise in suicides.

\subsection{Suicide Trends in Karachi}

"A single death is a tragedy, a million deaths is a statistic" ---Joesph Stalin

Suicides are rightly evaluated as a person's cry for help and attention. It is a person's lurking urge to get attention, which has always been denied by people close to him or her, besides accompanying factors, which augments their decision to attempt or commit suicide. It is inevitable that behind every attempt there are some socio-economic factors, but there are also cases where the mental health of a person drives him or her to attempt suicide. Our future generation is comprised of frustrated youth that feel betrayed by the amount of social pressure and due to the unjust system, contrary to what they are being taught. The feudal industrialists, corrupt bureaucracy and military have exploited the nation's resources through unequal and unjust distribution of resources and have failed to deliver on their promises. The poor and impoverished have lost their self-respect, patience and pride in being a 'Pakistani'. Therefore, they either resort to a life of crime, abuse and subservience, or facing their conscious, morals and ethical judgments and end up their lives.

In Karachi, the major reason for a suicide is the feeling of inanity of living. This feeling is connected with the situation of a certain society, particularly with the economic instability, ideological mess, unemployment, lack of infrastructure, poverty, personal relations and overestimation of public moral norms. Psychologists call this phenomenon "anonymity in a crowd." In other words, it is a situation, when a person feels terribly lonely, having a lot of friends, relatives and colleagues. There can be three forms of suicide distinguished: real, affective and demonstrative suicide. Real suicide is characterized with a strong wish of an individual to commit suicide. Affective suicide is characterized with being too emotional, while demonstrative suicide is used as a way to attract other people's attention. It would be wrong to say that all suicides are committed by mentally unbalanced people. There are a lot of intellectual individuals among them. However, a lot of them feel the loss of perspectives of life, and they can not accept the level of biological existence, for example a plant in a pot or an animal in a cage. As a fact, those who commit suicide have a rich and rather complicated inner world. Such people create a special spiritual environment, which is rather vulnerable for exterior influences. A slightest fracture of that environment is a tragedy for the people, who live in it. If they think that obstacles can not be surmounted, they surmise that there is only one way out for them to 'bid' farewell to life [4].

The accuracy of this dat a can further be judged by the various statements and facts provided by people during interviews such as Zia Ahmed Awan, who is an Advocate High Court and Human Rights Activist, Amber Farooq, who is a Psychiatrist at the Clinic of Psychology, Abdul Hai Field Officer at Human Rights Commission of Pakistan and Mazahir Hussain, who is the Regional Director of Human Rights, Government of Pakistan.

While speaking to Human Rights Activist (Zia Ahmed Awan) in an interview in July 2003 [5], he stated that the rate of suicides being committed in Pakistan is on the rise. Every day at least 4-5 cases of suicide are reported. Majority of the suicide attempters are minors. And even in the minors the rate of suicide amongst young boys is rising to a dangerous level. The reason that he gave for the rise in the suicide rate amongst them was that in our society even up to this day and age we put a lot of pressure on the male sex. We bring them up with the concept that they are males, the superior sex and the bread earner of the family, the caretaker and the head and that it is their job to protect the family and especially the weaker sex.

He further stated that there are various other reasons due to which the rate of suicide is increasing amongst the 
minors. To name a few dom estic violence, a volatile relationship between the elders, broken families and the disintegration of the joint family systems could also lead a child to commit suicide.

In July 2003, in an interview with Amber Farooq [6], a psychiatrist revealed that the overall sense of helplessness and frustration is not only evident in our society but we have come to a point where the implications of it are taking a toll on us. The bomb is fast ticking and we are silent spectators just waiting and watching. We know the problems yet we remain aloof to them simply distancing ourselves of them as if it's about other people and not us. The quest of creating a better society for not ourselves but for our coming generation has dwindled away because each one of us is selfishly surrounded in our own little web trying to pave a way for ourselves in this fast paced world of ours. Things have just boiled down to Me, Myself and I. The question that arises is "Who is to be blamed?" "Can we do something about it?" And the common answer to the question is "What can I do I' m so helpless?" We talk about conquering outer space not inner space. We shy away from issues, which need to be addressed and require our attention more than anything else. The general tendency is to satisfy our ego and follow the hypocritical norms of the society and conveniently brushing the core issues under the carpet. Even after 56 years of independence we as nation are bogged down by major issues such as lack of justice, providence of basic amenities such as water, electricity, lack of infrastructure, demons such as unemployment and poverty, lawlessness to name a few. Physical frustration leads to emotional and mental frustrations and then the vicious cycle goes on. These issues are yet to be looked into, understood and answered.

Abdul Hai [7], the field officer at HRCP yielded the following results in an interview held in July 2003, that our major misfortune is our complacency that injustices and heinous crimes cease to exist just because we don't talk about them. In fact they are very much there in society creeping up fast and encircling each one of us today. The reported cases of injustices, issues and crimes that are documented and brought in front of the public eye are just the tip of the iceberg not to mention millions of those that go unnoticed and are unspoken of due to the taboo still prevalent in our society. We strongly believe in see no evil, hear no evil but we forget to promise ourselves of the most important of the three to do no evil. We are building for ourselves a chronically depressed and oppressed society, which is like a pressure cooker where the pressure is mounting day by day. When it will burst and what implications it will bring with it remain to be seen however the symptoms of it are a warning signal in itself and for us to learn from.

We as a nation need to open our eyes to the potential threats that are arising. We may be living in the fast lane but we are not realizing that we may be leading to a dead end. If drastic measures are not taken then these problems are here to stay. Every suicidal attempt is a significant indicator of social stress and of one's personal dilemmas. Although religion serves as a strong deterrent to prevent one from thinking on these lines, it is a very weak moment when a person driven by pent up emotions and decides to take his own life. Those who are rescued must be welcomed back to life. As someone who endured the same experience commented he has returned after a close brush with death and now should be allowed to live peacefully.

During the interviews with different people such as nineteen from the families of the suicide victims, fourteen who attempted suicide and failed, three doctors who had treated suicide victims and six social workers, the following resu lts were surmised. As it is a sensitive issue, it was a very difficult experience to generate the interviews with the people who were directly or indirectly attached to this issue. Around 20 families were reluctant in parting with information, even mention ing their names and other personal information, some quoted their problematic situations very openly and on the other hand some did not even want to talk about it. So the data of those who allowed mentioning their personal information is attached in the appendix portion where as all the names are unrealistic.

Keeping in view the secondary information and after interviewing the above-mentioned people, one can conclude that there is an alarming rise of suicides in Karachi and the incidences of suicides and selfimmolation currently occurring in Pakistan/Karachi warrant more than mere expressing resentful displeasure and concern. Behind all this, there are very sensitive different causes which are mainly linked with the poverty, failure in love, failure in examination, marriage disputes, divorce, childlessness, economy, financial losses, unemployment, unhealthy conditions, family problems, inferiority complexes, domestic violence, police highhandedness psychological and mental problems etc. Results also show that not every suicide has a particular mental reason; even a normal person can commit suicide because of the unbearable problems [8].

The information collected revealed that the ratio of females is greater than males in attempted suicides, but the successful suicides are more in males, which is directly proportionate to the unemployment ratio and the burden of responsibilities, which were identified as the main causes of male suicides. As per information given in the Figure-1 and Figure-2, $75 \%$ of males and $25 \%$ of females committed suicide because of unemployment, $60 \%$ of males and $40 \%$ of females committed suicide due to love affairs, $95 \%$ of males and $5 \%$ of females committed suicide due to financial losses, $65 \%$ males and 35\% females committed due to poverty and $55 \%$ of males and $45 \%$ of females due to illegal relations. Divorce is the reason behind $30 \%$ of male suicides and $70 \%$ of female suicides and $53 \%$ of males and $47 \%$ of females committed suicide because of psychiatric problems [9]. 
Figure 1

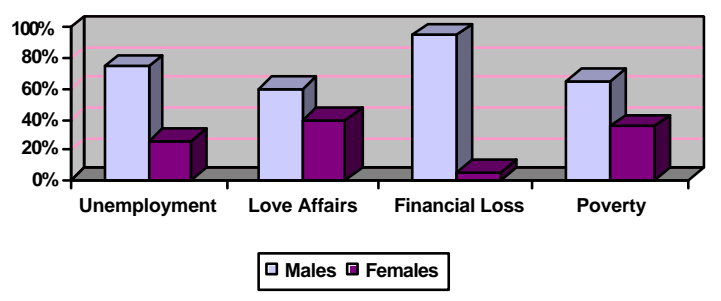

Figure 2

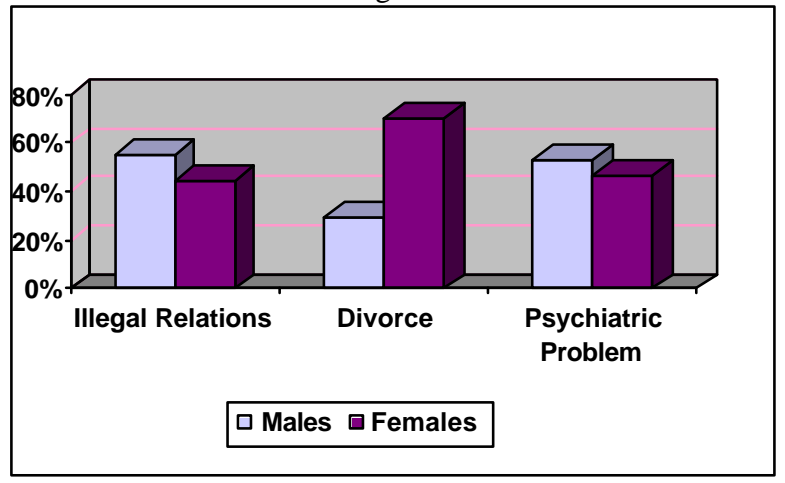

As per Figure- 3 and Figure-4, approximately $40 \%$ of the suicides occurred by taking the poisonous substances, such as neela thotha (copper sulphate), dhatura, DDT, kerosene oil and $20 \%$ by taking sleeping pills. The other common methods are: $20 \%$ by hanging, $7 \%$ by shooting, $10 \%$ by jumping from heights and $3 \%$ by self-immolation.

Figure 3

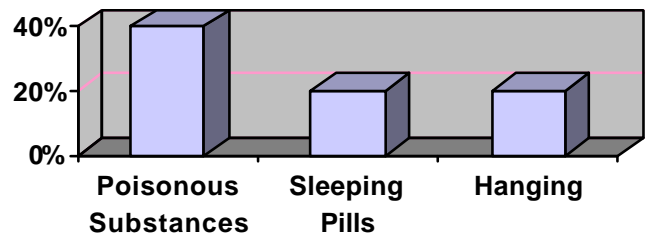

$\square$ Approximate Suicide Percentage

Figure 4

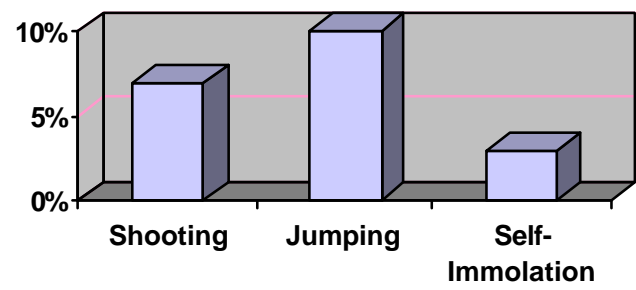

$\square$ Approximate Suicide Percentage

(Note: The above graphs are based on information from personal interviews.)

\section{CONCLUSION AND RECOMMENDATIONS}

Today, whether or not suicide is illegal depends upon the jurisdiction in which the question is asked. Although successful suicides are beyond the reach of the law, suicide is prohibited, for example, in most Islamic countries. On the other hand suicide has alw ays been more accepted in East Asian cultures. From past few years, there has been an alarming rise in suicides in Pakistan specially Karachi. The heinous trend is increasing day by day because of the fast globalization, isolation and the ups and downs in the economy. Suicides are more common in males due to the social, financial and other responsible causes whereas the attempted suicides are more common among females and the reasons are family problems, societal complications and divorces. Other major caus es are education lacking, love affairs, financial losses, economical issues, marital issues, poverty, illegal relationships and psychiatric problems. There are some protective measures taken by the government but there must be some improvements in the criteria like there should be helplines for people to share their problems and get solutions so that people will at least think before taking any wrong step and will have someone to guide them in a better way. In Pakistan, we are facing a dilemma that this sinful act is becoming the trend of our youth who are our future but no one is there to help them so that they will think of the brighter way of spending life rather than to kill themselves. Most of the married females are involved in it because of their marital problems and divorces, where as unmarried males are inclined towards this sin because of the unemployment and other burden of huge responsibilities. As a Muslim country, it is the duty of the State, media, religious scholars, teachers, social workers and political leaders to think of protecting basic values in the Muslim society, popularize Islamic teachings and arrange for moral and spiritual training of the public.

Keeping in view the above facts, following are some necessary recommendations, which need to be implemented by the concerned authorities as soon as possible:

- Authorities should reduce the free access to suicidal compounds and drugs.

- Physicians of the primary health care (early recognition and treatment of depression) should be trained properly to deal with patients.

- Families should be supportive because the family is the nucleus of all activities in an individual's life. Interpersonal conflicts and disturbed relations are the main factors for suicide. Family should listen to the victims, build strength by encouraging the person and minimize the conflicts.

- Most if not all hospitals should be equipped to handle suicides more effectively such as separate poisoning treatment departments etc.

- The media should act in a responsible way and present the problems of suicide by describing what leads to the act and the consequences and negative 
effects of such an action. As the media has a profound impact on the lives of people. (Radio and Television)

- Government and other concerned authorities should create new infrastructures so that it will provide employment to many of the unemployed people, as unemployment is one of the main causes of suicides.

- Introduce help lines, medical centers, community centers, talk groups, counselors who can help the victims of mental stress, suicide, or people whose loved ones have committed suicide and need help.

- Resiliency and coping skills should be taught to all suicide victims by trained technicians.

- Vibrant, effective and sincere youth policies should be designed and implemented by the government.

\section{REFERENCES}

[1] http://www.nap.edu/execsumm/0309083214.html \#sum Reducing Suicide “A National Imperative 2002”
[2] http://www.nap.edu/execsumm/0309083214.html \#sum

[3] Shamaila Ijaz Haider \& Ijaz Haider, Pakistan Journal of Medical Sciences, Volume 17, No.3, Pakistan http://www.pulsepakistan.com/pakjmedsciences/j ulsep01/article4.html\#top

[4] Daily Dawn, [July 10, 2003] Welcome Back to Life, Article Karachi

[5] Zia Ahmed Awan, Human Rights Activist

[6] Abmer Farooq, Psychiatrist, Clinic of Psychology, Karachi

[7] Abdul Hai, HRCP, Karachi

[8] Sharjeela Tariq Dr, General Psysician Medicine, Abbasi Shaheed Hospital, Karachi

[9] Personal Interviews with 50 Victims/Families in Karachi 